\title{
Dialectal variation in the expression of que in si-que 'yes that' contexts across Spanish: The case of some Latin American Spanish varieties
}

\author{
Julio Villa-García and Raquel González Rodríguez² \\ 1 University of Manchester, Department of Linguistics and English Language, Samuel Alexander Building, School of Arts, \\ Languages and Cultures, Faculty of Humanities, UK \\ 2 Universidad Complutense de Madrid, Departamento de Lengua Española y Teoría de la Literatura, Facultad de \\ Filología, Edificio D, Plaza Menéndez Pelayo, Madrid, ES \\ Corresponding autor: Julio Villa-García (julio.villa-garcia@manchester.ac.uk)
}

This paper investigates dialectal microvariation across the Spanish-speaking world in terms of the presence/absence of que in si-que contexts. The function of this construction is to signal the speaker's commitment to the truth of the proposition. In this connection, we argue that the syntactic account recently proposed by Villa-García \& González Rodríguez (2020) for polarity-encoding sí 'yes' on the one hand and for si-que 'yes that' sequences in Iberian Spanish on the other readily extends to a number of Latin American varieties where que in si que is syntactically present albeit unpronounced (i.e., si $\varnothing /$ que), although it can be overt as well. We provide a variety of syntactic arguments together with Phonetic-Form- and LogicalForm-related arguments to this effect, and show that the dialectal split brought to light here is consonant with a view of (micro-)variation whereby Phonetic Form spellout plays a key role (Barbiers 2009; Rizzi 2013; Rizzi \& Bocci 2017; inter alia).

Keywords: microvariation; dialectal variation; polarity; sí que; sí; Latin American Spanish; Iberian Spanish

\section{Introduction}

The particle sí 'yes' and the sequence sí que 'yes that' have been deemed interchangeable in constructions such as the ones illustrated in (1), which prima facie do not appear to involve syntactic or semantic differences (e.g., Carbonero Cano 1980: 167; Leonetti \& Escandell-Vidal 2009: 200; RAE-ASALE 2009: 3004).

$$
\begin{aligned}
& \text { a. María sí llegó a Buenos Aires. } \\
& \text { María yes arrived to Buenos Aires } \\
& \text { 'María did arrive in Buenos Aires.' }
\end{aligned}
$$

b. María sí que llegó a Buenos Aires. María yes that arrived to Buenos Aires 'María certainly arrived in Buenos Aires.'

However, in spite of the apparent parallelism between (1)a and (1)b, recent research has shown that sí and sí que in Spanish are critically different from each other in terms of their behavior and distribution alongside their meaning (Hernanz 2007; Batllori \& Hernanz 2013; Villa-García \& González Rodríguez 2020). 
In particular, Batllori \& Hernanz (2013) and Villa-García \& González Rodríguez (2020) provide a host of arguments that sí in (1)a is an emphatic/focal positive polarity marker, a function typically carried out in English by a stressed auxiliary (i.e., did in the English translation of (1)a). However, sí que, illustrated in (1)b, does not encode polarity and instead signals the speaker's commitment to the truth of the proposition; (1)b can thus be paraphrased as 'it is truly the case that [Mary arrived in Buenos Aires],' where the bracketed constituent corresponds to the proposition (see also Poletto \& Zanuttini 2013 for a similar claim for Italian sì che). We adopt the analysis proposed by Villa-García \& González Rodríguez (2020) for sí and sí que in Iberian Spanish, which is sketched in (2). ${ }^{1}$ Note that (2)a assumes that the polarity element sí is initially generated in the head of the polarity-encoding projection $\Sigma \mathrm{P}$ and from there it rises to FocusP in order to satisfy its focal nature, although nothing in this paper hangs on this. As for (2)b, si que is merged in a higher position (see Section 2 for a note on the label of XP in (2)b).

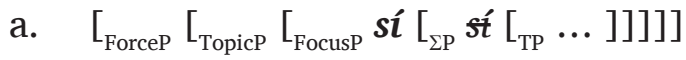

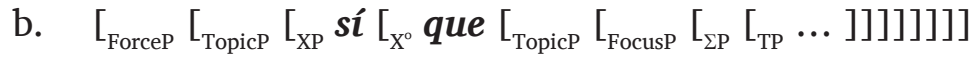

Importantly, this analysis makes a number of correct predictions regarding Iberian Spanish, such as the ability of negative propositions to occur below si que, but not below $s i$, as in (3). This is precisely what would be expected under (2)a/(2)b, wherein sí marks emphatic affirmative polarity and sí que, rather than encoding polarity, indicates the speaker's commitment to the proposition, be it positive or negative.

$$
\begin{aligned}
& \text { Ahora sí *(que) ya no pueden fastidiarme. } \\
& \text { now yes that already not can bother-CL } \\
& \text { 'Now they clearly can't bother me anymore.' }
\end{aligned}
$$

In this paper, we show that some Latin American varieties permit (3) without que, which amounts to saying that such varieties exhibit a version of sí que where que is physically absent (i.e., sí Ø), effectively making it superficially identical to polarity-encoding-sí sentences in certain environments. However, as we will see, there are important differences in the relevant Latin American dialects between polarity-encoding sí and sí $\varnothing$, which, we argue, is the que-less variant of Iberian Spanish sí que.

It is of note that the negative head no can be preceded by sí in all dialects providing that sí is followed by a pause/intonational break, as in (4).

$$
\begin{aligned}
& \text { Sí, no pueden fastidiarme. } \\
& \text { yes not can bother-CL } \\
& \text { 'Yes, they can't bother me.' }
\end{aligned}
$$

As noted by Brucart (1999) and González Rodríguez (2009), when sí is followed by a prosodic boundary, this particle is a proform and does not display the same distribution as the polarity marker that is integrated in the predicate, despite their homophony and related meaning. Our analysis applies only to the second type of sí (cf. (1)a), not to proform sí (cf. (4)). ${ }^{2}$

\footnotetext{
${ }^{1}$ Batllori \& Hernanz (2013) propose the same structure for sí. However, these authors argue that sí que is placed in ForceP. See Villa-García \& González Rodríguez (2020) for arguments against sí que being located in ForceP.

${ }^{2}$ The proform sí shows a different distribution from that of the polarity marker that is integrated in the predicate. In addition to the possibility of being followed by other polarity markers (see the contrast between (3) and (4)), they differ regarding to their autonomy: the proform can occur as an utterance by itself (see (i)),
} 
Building on the findings of Hernanz (2007), Batllori \& Hernanz (2013), and Villa-García \& González Rodríguez (2020), we investigate sí, sí que, and sí Ø in varieties including Colombian, Mexican, and Peruvian Spanish, and submit that the Spanish spoken by speakers of these dialects also displays (a version of) the sí-que construction, with que being able to remain silent. ${ }^{3}$ This pattern is exemplified in (5), where sí is a formal mark of the commitment of the speaker to the truth of the proposition, as shown in the English translation. Note that the polarity of this example is negative, despite the presence of the word sí (much like in Iberian Spanish examples with que, shown in (3), which would be fully grammatical in the relevant Latin American varieties without que). This confirms that (5) features sí $\emptyset$, as argued below, rather than the emphatic polarity marker sí.

(Song by Orquesta Típica Juventud, 1975, Peru)

No me digas que no sabes. Eso sí no te lo creo.

not CL tell that not know that yes not CL CL believe

'Don't tell me you don't know. That, I certainly do not believe!'

Examples like (5) stand in glaring contrast to similar cases featuring sí que in Iberian Spanish (cf. (3)), where que must be present, pointing to an important dialectal difference in terms of the lexicalization of que in si-que contexts: whereas que is obligatory in Iberian Spanish, in some Latin American varieties, que can be absent (si $\varnothing$ ) or present (si que). The example in (5) illustrates the first option; we provide examples of said varieties where the complementizer is present in due course.

Our main theoretical claim in this paper is that the Iberian Spanish facts and the novel Latin American Spanish facts can be accounted for in a uniform fashion, the difference between said varieties being that in the latter case, que in sí que can normally remain silent in $\mathrm{P}$ (honetic)F(orm), as (6)b assumes.

whereas the polarity marker that is integrated in a sentence cannot (see (ii)). As illustrated by the examples in (i) and (ii), the two particles are used in different contexts. The proform is typically used to answer questions; the other particle is used to refute a previous utterance (see Brucart 1999 and González Rodríguez 2009 for a more detailed description of the distribution of both forms; see also fn. 18 for additional evidence). Note that languages such as English employ different strategies in these cases.

(i)

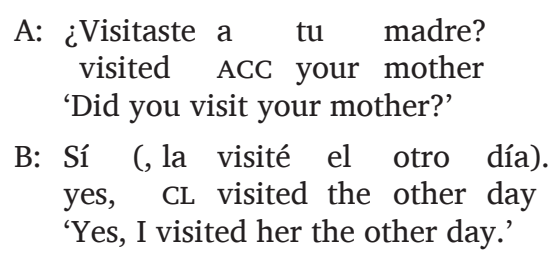

(ii)
A: No visitó a su madre. not visited ACC her mother 'S/he did not visit her mother.'
B: Sí *(visitó a su madre). yes visited ACC her mother 'S/he did visit her mother.'

\footnotetext{
${ }^{3}$ The exact extent of diatopic variation in this regard is beyond the scope of this paper. This is not a trivial matter, as Latin American varieties do not necessarily refer to countries, but to areas (e.g., in Colombia, there are notable dialectal differences between the Spanish spoken in the Caribbean area and in the Andean area). In our investigation, in addition to relying on naturally occurring data and on data from published literary works, songs, TV shows, and TV series, we have consulted two speakers from Colombia, one from Ecuador, two from Mexico, and two from Peru (age range: 26-50), who have kindly shared their introspective judgments with us. Although we did not find discrepancies in their judgments, further research will determine whether the rather stable judgments we have obtained hold, and whether they extend to different Latin American varieties.
} 


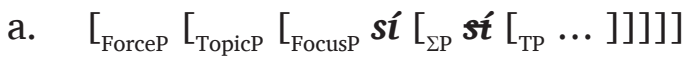

$$
\begin{aligned}
& \text { b. }\left[_{\text {ForceP }}\left[_{\text {TopicP }}\left[{ }_{\mathrm{XP}} \boldsymbol{s i ́}\left[_{\mathrm{X}^{\circ}} \text { que }\left[_{\text {TopicP }}\left[_{\text {FocusP }}\left[{ }_{\Sigma \mathrm{P}}\left[\mathrm{T}_{\mathrm{TP}} \ldots\right]\right]\right]\right]\right]\right]\right]^{4}\right.
\end{aligned}
$$

This paper is organized as follows: in Section 2, we outline the analysis and predictions of sí vs. sí que in Iberian Spanish, based on the evidence provided by the existing works on the topic. In Section 3, we present Colombian, Mexican, and Peruvian Spanish data where que can be absent in sí-que sequences. In Section 4, we provide an analysis of the facts and argue against competing proposals. We also discuss the issue of microvariation in the expression of que, along with a proposal as to how to parameterize the observed variation. In Section 5, we conclude the paper.

\section{Si vs. sí que in Iberian Spanish}

In the spirit of Rizzi's (1997 et seq.) fine structure of the left periphery, Villa-García \& González Rodríguez (2020) adopt the view that sí que sits in a projection higher than FocusP, where polarity-encoding sí is assumed to be located after moving to that position from $\Sigma$ P (Hernanz 2007), as in the highly simplified structure in (7). ${ }^{5}$

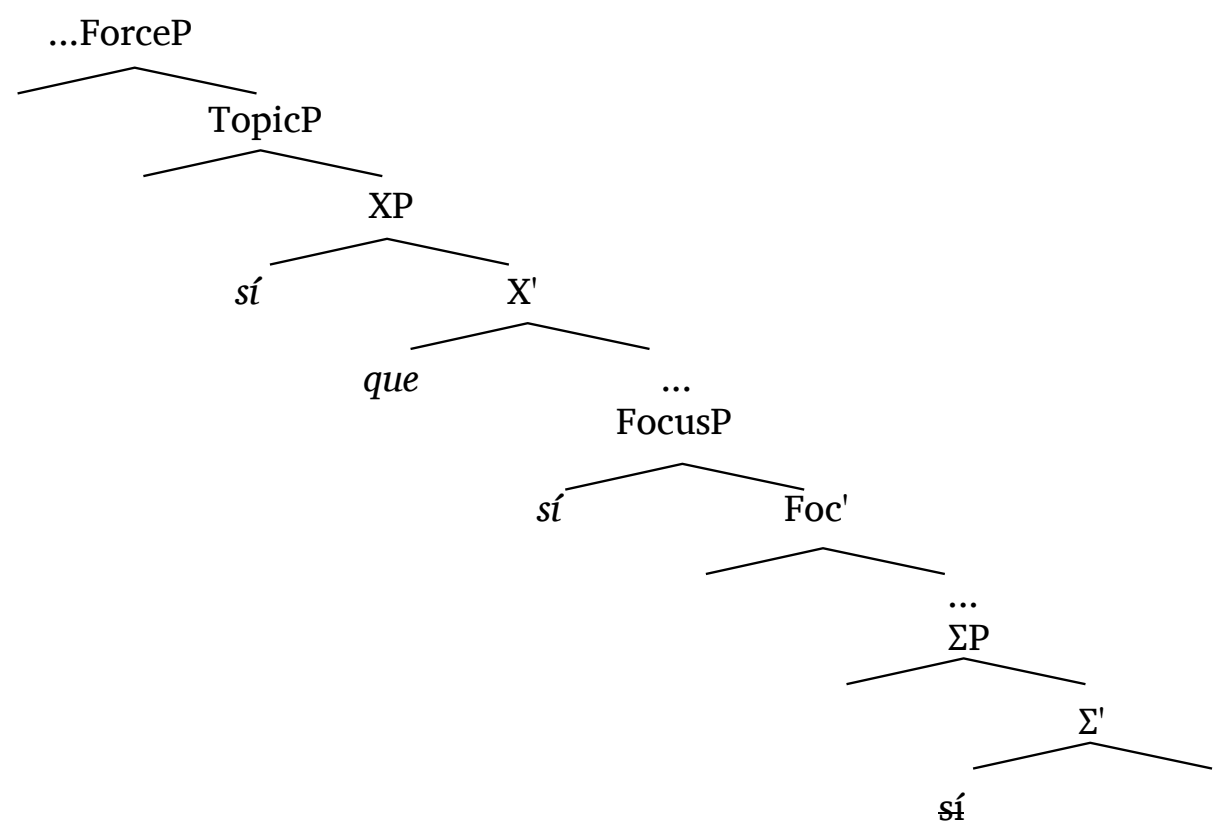

Although Villa-García \& González Rodríguez (2020) do not specify the label of the XP projection in (7), leaving it for future research, it would be possible to explore two options regarding the nature of this projection. As Villa-García \& González Rodríguez note, an

\footnotetext{
${ }^{4}$ Until the account is presented in Section 4, we employ the more theory-neutral form $\emptyset$ to represent the physical absence of que in the main text.

${ }^{5}$ As an anonymous reviewer points out, a logical question to pose is whether or not que is a complementizer. In light of the analysis in (7), the categorial status of que is not fully clear. In order to determine this issue, a detailed study of que in the sequence sí que and in other related structures (por supuesto que 'of course that,' iQué alto que eres! 'How tall that you are!') should be conducted in future research (see Villa-García in preparation). An argument for the analysis of que as a complementizer in the configuration at issue is that sí que introduces more structure (i.e., a full sentence/clause), in contrast to polarity-encoding sí (Villa-García \& González Rodríguez 2020). Thus, the fact that what we get is sí que + [sentence] is symptomatic of que being the head of the upcoming clause (see the authors for discussion of the historical development of the construction, which may have developed out of the affirmative polarity particle plus a clause/sentence (si $+[q u e . .])$.$) . Since complementizers can be omitted in some declarative clauses in some diachronic and$ present-day varieties such as Mexican Spanish (Villa-García in preparation and the references cited there), it is not surprising that in sí $\emptyset$ cases, a complementizer is present, albeit unpronounced (i.e., sí que). In any case, we will employ the label complementizer for expository reasons.
} 
option would be to identify this projection with AssertiveP, a projection proposed by Ambar (2002). According to this author, AssertiveP is the projection in which metalinguistic negative particles are placed (see Villa-García \& González Rodríguez 2020, for parallels between the elements assumed to occur in AssertiveP and sí que). Ambar argues that this projection is located between TopicP and FocusP, which fits in with the proposal in (7). A second option would be to propose that XP in (7) is related to a Speech Act Projection, as an anonymous reviewer points out (see Haegeman \& Hill 2013; Wiltschko \& Heim 2016; Miyagawa 2017; and Jiménez-Fernández \& Issever 2019, among many others, for a syntactic approach to discourse). In order to establish this correlation, a detailed comparison between sí que and the particles typically associated with the Speech Act Projection should be carried out. It would also be necessary to study if that proposal could account for the word order patterns of si que, a task that we leave for future research.

The analysis in (2)/(7) makes a number of correct predictions regarding Iberian Spanish. We will only review the most relevant ones here; the reader is referred to Villa-García \& González Rodríguez (2020) for further predictions and empirical evidence. Firstly, (7) captures the fact that sí and sí que convey different meanings. While sí invariably marks (focal) positive polarity and therefore the proposition is affirmative, the proposition embedded under sí que need not bear positive polarity. This is because sí que is not a positive polarity marker, but rather a means of signaling the speaker's conviction that the proposition is true, irrespective of whether the proposition is affirmative or negative. The fact that sí, but not sí que, encodes polarity is shown by its incompatibility with the negative polarity particle no. As noted, sí que, but not sí, can co-occur with this particle in Iberian Spanish. This is shown by (8), which indicates that when followed by que, sí does not denote positive polarity (see also (3) above).
a. Aquí sí que no nieva.
here yes that not snows
'It is truly the case that it does not snow here.'
b. *Aquí sí no nieva.
here yes not snows
'It certainly does not snow here.'

In addition to this major semantic difference between sí and sí que, the analysis in (7) predicts that these elements should have a different distribution, and this prediction is again borne out. First of all, if we assume the structure in (7), we can also explain the contrast in (8) by appealing to syntactic reasons, since in (8)b, sí and no compete for the same position, namely the head of $\Sigma \mathrm{P} .{ }^{6}$ By contrast, this problem does not arise in (8)a, since sí que is placed in a higher, different position (i.e., XP in (7)). It must also be noted in passing that (7) can also account for the fact that when si que co-occurs with no, the order must be the one in which si que precedes the negation. This is illustrated by the contrasting examples in (8)a and (9).

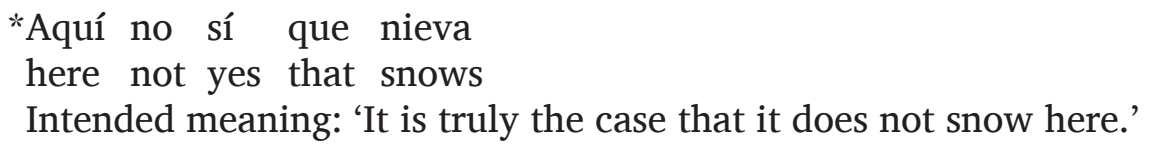

Another piece of evidence arguing for (7) comes from subject-verb inversion. Sí is focal and as such requires adjacency with the verb (Hernanz 2007; Batllori \& Hernanz 2013).

\footnotetext{
${ }^{6}$ (8)b is fully grammatical in Iberian Spanish if only one of the polarity markers (sí or no) occurs, as predicted if they originate in the same syntactic position.
} 
In much the same way as in constituent questions, the underlined subject Juan in (10)a needs to occur postverbally in the presence of the emphatic/focal polarity particle sí. By contrast, the occurrence of the subject between si que and the verb does not lead to an ungrammatical outcome, as indicated by $(10) \mathrm{b}$. Although (10)b is a marked sentence for some speakers (\%), as pointed out by a reviewer, it stands in stark contrast with (10)a (see Villa-García \& González Rodríguez for further discussion and exemplification from corpus data).
a. Al final sí \{*Juan\} compró \{Juan\} patatas \{Juan\}. at.the end yes John bought John potatoes John 'In the end John did buy potatoes.'
b. ${ }^{\%} \mathrm{Al}$ final sí que Juan compró patatas. at.the end yes that John bought potatoes 'In the end, John certainly bought potatoes.'

Much like preverbal subjects, other preverbal constituents such as (multiple) dislocated adverbials can follow the si-que sequence, as the metalinguistic example from the main text of Hualde et al. (2010: 288) in (11) demonstrates.
Aquí sí que aún hoy, en la medida en que se conserva la here yes that even today in the measure in that CL conserves the forma tradicional de hablar, podemos...
form traditional of speak can
'Here, even today, to the extent that the traditional way of speaking is preserved, it is truly the case that we can...'

Finally, the analysis in (7) makes the claim that a focal element should be able to occur below sí que. Since sí in this account is assumed to be a focal polarity particle in FocusP, then in principle we should be able to find occurrences of the sí-que-sí sequence. This prediction is corroborated by the following data, akin to those reported in Villa-García \& González Rodríguez (2020). The order in cases like (12) is always sí que > sí rather than sí > sí que, precisely as predicted by (7). ${ }^{7}$

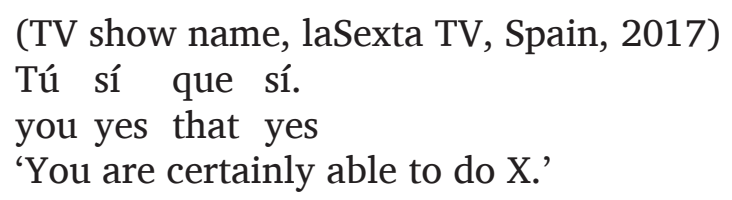

As expected, other focal phrases are also legitimate in post sí-que position, as indicated by (13). The examples in (14) show that sí does not display the same behavior.
a. Tú sí que también tienes tela. you yes that also have fabric
'It is truly the case that you are a pain.'
b. A mí sí que NI DE COÑA me van a ascender. ACC me yes that NO OF JOKE CL go to promote 'Under no circumstances will they promote me.'

\footnotetext{
${ }^{7}$ A reviewer notes that the impossibility of having the combination sí + sí que could be explained by haplology, that is, by a constraint against adjacent homophonous forms (we resort to this type of analysis in Section 4 in order to account for the ungrammaticality of "sí sí in varieties that accept sí no). However, a haplology-based explanation of *sí sí que is called into question by the fact that the sequence no + sí que is also ungrammatical (see (9)).
} 

a. *Tú sí también tienes tela. ${ }^{8}$ you yes also have fabric 'You are also a pain.' ACC me yes NO OF JOKE CL go to promote 'Under no circumstances will they promote me.'
b. *A mí sí NI DE COÑA me van a ascender.

In the next section, we turn to the novel dialect data that constitute the object of study of this paper.

\section{Dialectal variation: Some Latin American Spanish varieties}

Moving away from Iberian Spanish, in certain varieties of Latin American Spanish, the bare form sí $\emptyset$ can be used instead of the form sí que, as shown by the data in (15) (see also (5) in Section 1).

$$
\begin{aligned}
& \text { (Song by Los Relámpagos del Norte, 1993, Mexico) } \\
& \text { Eso sí nunca podrás. } \\
& \text { that yes never will.be.able.to } \\
& \text { 'That, you will certainly never manage to...' }
\end{aligned}
$$

This occurs in contexts where, given our previous discussion, which focused on Iberian Spanish data, we would expect que to occur. In other words, in some varieties, sí is frequently used in the place of sí que (i.e., not as an emphatic polarity element, but as formal marker of the speaker's commitment to the proposition).

It is of note that the presence of que is also legitimate in the varieties at issue, as shown by the corpus examples furnished in (16). These cases are, in effect, identical to their Iberian Spanish counterparts with respect to both the form and meaning of si que.

a. (CORPES XXI, Isaac Goldemberg. El nombre del padre, Lima, Peru:

Alfaguara, 2001)

¡Esto sí que no lo puedo creer!

this yes that not CL can believe

'I certainly cannot believe this!'

b. (CORPES XXI, Gabriel Velasco, Alondra de ojos en las alas, Mexico City, Mexico: La rana, 2001)

Yo no sé por qué regresé acá, pero ahora sí que no vuelvo. I not know why returned here but now yes that not return 'I don't know why I returned, but now I certainly do not return.'

Accordingly, Latin American varieties that permit sequences where que is absent also allow the presence of the complementizer in the same contexts (see Section 4 for environments where the complementizer must actually be present in those varieties). In other words, in these varieties, (17)a and (17)b are interchangeable. As we will see, however, the relevant Latin American varieties also possess polarity-encoding sí, much like Iberian Spanish.

$$
\begin{aligned}
& \text { a. Esta pregunta sí que no la contestó. } \\
& \text { this question yes that not CL answered }
\end{aligned}
$$

${ }^{8}$ (14)a would in principle become grammatical if an intonational break (represented orthographically by a comma) occurred afer sí, in which case this instance of sí would be a proform. However, it is important to highlight that this is not our intended structure. 
b. Esta pregunta sí no la contestó.

this question yes not CL answered

Both: 'S/he certainly did not answer this question.'

In the following subsections, we take a closer look at certain syntactic and semantic aspects of the que-less paradigm in said varieties.

\subsection{The construction si $\emptyset$}

The following sentences further indicate that que does not need to occur (at least overtly) below sí in sí-que cases in Spanish varieties spoken in (at least) Colombia, Mexico, and Peru (see also the data in Campos 1992: 332). ${ }^{9}$ Recall that the meaning of sí in (18) is conveyed via sí que in Iberian Spanish and that the absence of que in the relevant Latin American varieties is optional; thus, the complementizer could be introduced in (18) without giving rise to any syntactic or semantic change.

a. (Rafael Delgado, Angelina, Mexican Spanish, 1983)

A eso sí no puedo acostumbrarme, al chocolate malo. to that yes no can get.used to.the chocolate bad 'I certainly cannot get used to that, to bad chocolate.'

b. (Juan Gabriel Vásquez, El ruido de las cosas al caer, Colombian Spanish, 2011) Eso sí no sé. that yes no know 'I certainly do not know that.'

That sí in (18) is an instantiation of the sí-que construction (and not a polarity particle) is straightforwardly corroborated by the fact that the polarity of the proposition below si $\varnothing$ is negative in spite of the presence of the word sí, much like in Iberian Spanish cases like (8)a above. In fact, there is independent evidence corroborating the negative polarity of the sentences in question. As observed by Brucart (1999), in cases of TP ellipsis with a polarity particle, if the first conjunct is negative and the second conjunct is also negative, tampoco 'neither' must be used in the second, elliptical clause (and, conversely, también 'also/too' must be used if the polarity of both conjuncts is positive). Now, if we add to the sentences in (18) another clause including the polarity element también 'too' or tampoco '(n)either,' the negative element tampoco must be used, as expected if the examples in (18) are indeed negative, despite the presence of sí. This is shown in (19). The judgments reported for these examples do not vary if we introduce que between sí and no.

a. A eso sí no puedo acostumbrarme, al chocolate malo, y to that yes no can get.used-REFL to.the chocolate bad and al amargo *también/ tampoco.

to.the bitter too neither

'I certainly cannot get used to that, to bad chocolate, nor can I get used to bitter chocolate either.'

\footnotetext{
${ }^{9}$ Such sentences are also attested, though much less frequently, in the speech of some Iberian Spanish speakers. Although our focus is Colombian, Mexican, and Peruvian Spanish, due to the results of our corpus searches, some speakers of other varieties, such as Argentinean, Chilean, Costa Rican, and Ecuadorian Spanish also report que-less sí cases. It is not our intention to treat these varieties as a single monolithic entity, although we have found a similar behavior in the relevant respects. One related area where there may be geographic differences has to do with the structure no que no (lit. 'not that not'), which is in use in some dialects. In Argentinean and Mexican Spanish, for example, no que no is employed to ironically affirm something that had previously been denied. The neg.-that-neg. pattern is widely attested in Catalan (Batllori \& Hernanz 2013) and in Italian (Poletto \& Zanuttini 2013). We leave a comprehensive study of diatopic variation for future work (see also fn. 3).
} 
b. Eso sí no sé, y esto *también/ tampoco. that yes no know and this too neither 'I certainly don't know that, and I don't certainly know this either.'

The possibility of having the sequence sí no in Colombian and Mexican Spanish is further supported by data from the CREA (Corpus de Referencia del Español Actual) corpus, which contains examples such as the ones in (20).

a. (Wilebaldo López, Vine, vi... y mejor me fui, Mexico, 1988, CREA)

Pero de pestilencia sí no te escapas.

but of stench yes no CL escape

'But you certainly will not escape from stench.'

b. (El Tiempo, Colombia, 01/12/1991, CREA]

Ahí sí no se tendrá en cuenta el proceso de apertura. there yes not CL will.take into account the process of opening 'The process of opening will certainly not be taken into account there.'

In the next subsection we explore the issue of the distinction between si $\varnothing$ (si que) and polarity sí in Colombian, Mexican, and Peruvian Spanish. ${ }^{10}$

\subsection{Sí vs. si $\emptyset$ in Latin American varieties}

Having mainly looked at examples involving negation, several issues arise in light of Latin American Spanish examples like (21) (pronounced with no intonational break after $s i$ ), where the polarity of the clause is positive:

(Netflix TV series The House of Flowers/La casa de las flores, Episode 1, Season 1, Mexico, 2018)

Ahora sí la Roberta resultó una aguafiestas.

now yes the Roberta resulted a wet blanket

'Now it is truly the case that Roberta ended up being a wet blanket.'

As noted by Villa-García \& González Rodríguez (2020), an anticipated problem when studying sí/sí que contrasts in Iberian Spanish is that, due to their seeming interchangeability, traditional grammars have usually treated sí/sí que as variants of one and the same underlying phenomenon, which is typically represented by the use of brackets around que (cf. sí (que)) in traditional descriptions. The Latin American Spanish case exemplified in (21) further exacerbates this problem, since the polarity of the proposition embedded by sí $\varnothing$ can be positive and thus, sí $\varnothing$ can easily be taken to instantiate polarity-encoding sí instead. In (21), the presence of the preverbal subject after sí allows us to conclude that sí is not a polarity marker, that is, that sí $\emptyset$ does not instantiate sí, notwithstanding their similarity in outward appearances. As shown in Section 2, sí, unlike sí que, is a focalized constituent and therefore, requires adjacency with the verb (see below for examples involving the polarity-encoding particle sí, not sí $\emptyset$, in said Latin American varieties).

\footnotetext{
${ }^{10}$ An additional argument in favor of treating these cases as sí-que configurations in disguise comes from the fact that when the negation appears, the topic above si que is obligatory (for reasons that are far from clear; see RAE-ASALE 2009 and Villa-García \& González Rodríguez 2020). According to our native-speaker consultants, the examples furnished in this section require a topical element, suggesting that we are dealing with clear cases of si- $\emptyset$-no configurations. In this connection, it is important to recall that cases such as (4), where proform sí is followed by a prosodic break and then by a negated sentence, do not require a preceding topic. Therefore, this substantiates the claim that the examples from Latin American Spanish offered throughout this section (which furthermore do not occur with an intonational break after sí $\varnothing$ ) do not constitute cases like (4).
} 
As an anonymous reviewer notes, this proposal appears to make a prediction regarding the interpretation of (21): if the subject were postverbal, sí would in principle mark positive polarity, not the speaker's firm belief that the propositional content is true. Our informants do note a semantic difference depending on whether the subject is preverbal or postverbal. However, they cannot explain clearly what this difference is, which can be due to the fact that distinguishing between positive polarity and the commitment of the speaker is subtle, especially in affirmative contexts. Similarly, the difference may well be motivated by the different information-structural statuses of preverbal and postverbal subjects. ${ }^{11}$

The problem of determining whether we have a polarity marker ( $s \hat{\text { ) }}$ or not (si $\varnothing)$ when the complementizer is not present in varieties of Colombian, Mexican, and Peruvian Spanish is even worse in a sentence without a preverbal subject intervening between sí and the verb, such as (22)a. Anticipating the upcoming theoretical discussion and based on the analysis pursued for Iberian Spanish in Section 2, in principle two underlying structures should exist, with two different meanings, as shown by the English translations (though evidently not easy to tell apart). The two underlying structures are given in (22)b and (22)c. ${ }^{12}$
a. Ahí sí voy.
there yes go
'I AM going there.' / 'I am certainly going there.'
b. (Emphatic positive polarity)
$\left[_{\text {ForceP }}\left[{ }_{\text {TopicP }}\right.\right.$ ahí $\left[_{\text {FocusP }}\right.$ sí $\left[_{\Sigma \mathrm{P}}\right.$ sí $\left[{ }_{\mathrm{TP}}\right.$ voy $\left.\left.\left.\left.]\right]\right]\right]\right]$
c. (Speaker's commitment to the proposition)

$$
\left[_{\text {Forcep }}\left[_{\text {TopicP }} \text { ahí }\left[_{\mathrm{XP}} \text { sí }\left[_{\mathrm{X}^{\circ}} \emptyset / \mathbf{q u e}\left[_{\mathrm{TP}} \text { voy }\right]\right]\right]\right]\right]
$$

A potential question to raise at this juncture is whether Latin American Spanish varieties where que can be omitted in the contexts above actually altogether lack the si que/ $\varnothing$ construction and only employ the focal affirmative marker sí, in such a way that these varieties have (22)b but not (22)c. However, this possibility cannot be right. After all, several examples furnished above involve an instance of negation below sí and are interpreted as bearing negative polarity, which refutes the claim that sí in such cases encodes polarity. Likewise, que can optionally surface in these varieties, which provides direct evidence for the existence of sí-que configurations. Moreover, as will be shown below, in some syntactic environments, que is obligatory even in the relevant dialects spoken in Colombia, Mexico, and Peru.

Conversely, then, could it be that these Latin American varieties use only sí $\emptyset$ (cf. (22)c), instead of the two constructions in (22)b,c? The answer to this question turns out to be negative as well. First of all, the relevant varieties can also have examples akin to (12), where sí que co-occurs with the emphatic positive polarity marker, as in (23), suggesting that we are dealing with the familiar sí-que construction followed by sí. (We return to these cases in the following section.)

\footnotetext{
${ }^{11}$ Be that as it may, an issue that casts doubt on this prediction is that si que in Iberian Spanish is also compatible with postverbal subjects, as in (i):

(i) Ahí sí que puso bancos el consejero.

there yes that put benches the counsellor

'The regional minister certainly placed benches there.'

${ }^{12}$ As a reviewer points out, it would be interesting to know the (preferred) interpretation of (22)a. However,
as noted above, the distinction between the two readings is subtle, which makes it difficult to obtain data in
this regard. Context certainly seems to play an important role (see Villa-García \& González Rodríguez 2020).
} 

Ahora sí que sí. now yes that yes
'Now it is truly the case that X.'

Furthermore, Villa-García \& González Rodríguez (2020) capitalize on cases involving ellipsis with a polarity particle (Brucart 1999), which, as the name indicates, feature a polarity element as the licensor of ellipsis. These cases are illustrated in (24).
A Arequipa no voy, pero a Lima sí.
to Arequipa not go but to Lima yes
'I'm not going to Arequipa, but I am going to Lima.'

Cases like these are attested throughout the Spanish-speaking world, as shown by the examples provided by RAE-ASALE (2009: 3006-3007), and clearly involve a contrasting polarity marker in the second clause. This is further substantiated by the fact that sí que, which in principle covaries with sí $\varnothing$ in some Latin American Spanish varieties, cannot occur in cases like the following, which have been analyzed as a context in which the verb is elided (Brucart 1999; Depiante 2004; Villa-García \& González Rodríguez 2020):

$$
\begin{aligned}
& \text { a. No compré carros, pero sí departamentos. } \\
& \text { not bought cars but yes apartments } \\
& \text { 'I didn't buy cars, but apartments.' } \\
& \text { b. "No compré carros, pero sí que departamentos. }{ }^{13} \\
& \text { no bought cars but yes that apartments } \\
& \text { c. "No compré carros, pero sí que sí departamentos. } \\
& \text { not bought cars but yes that yes apartments }
\end{aligned}
$$

In (25)b, if sí were always the que-less variant of sí que, we would in principle expect que to be able to be pronounced, contrary to fact. What is more, if such ellipsis cases must involve polarity particles, as is standardly assumed in the literature, we would expect the bona fide focal affirmative polarity marker to be instantiated in (25)a, rather than sí $q u e / \varnothing$, which does not serve the function of indicating the polarity of the clause. This is the reason why (25)a is acceptable but not (25)b: only in the first case do we have a genuine polarity marker, as required by this type of ellipsis. As shown in (25)c, the combination sí que sí is rejected in these contexts. We would like to suggest that the ungrammaticality of (25)c is due to the parallelism requirement on ellipsis (i.e., we would expect coordination at the clausal level with sí que), although the data merit further attention. Note in passing that cases like (23) above (Ahora sí que sí 'Now it is truly the case that $\mathrm{X}$ ') are also interpreted as elliptical clauses, which is exactly what would be expected, given that the polarity particle sí (the ellipsis licensor) occurs below sí que (and, as shown below, examples with other ellipsis-licensing polarity particles, namely no 'not,' también 'also/too,' and tampoco 'neither,' are also documented).

Lastly, it is important to note that si $\varnothing$ configurations do not require the inversion that one would expect in the case of a bona fide focal sí. This is indicated by (21), repeated here again in (26), which exhibits a preverbal subject intervening between sí $\varnothing$ and the verb.

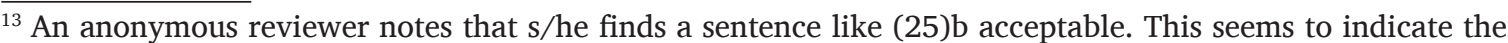
existence of variation regarding this construction. To us, this example is completely out and, crucially, the speakers from the varieties studied here also reject this structure.
} 
(26) (Netflix TV series The House of Flowers/La casa de las flores, Episode 1, Season 1, Mexico, 2018)

Ahora sí la Roberta resultó una aguafiestas.

now yes the Roberta resulted a wet.blanket

'Now it is truly the case that Roberta ended up being a wet blanket.'

However, Latin American Spanish varieties such as Argentinean, Colombian, Ecuadorian, Mexican, and Peruvian Spanish do have focal sí requiring adjacency with the verb. By way of illustration, speakers report obligatory inversion in cases like (27), which again involve a contrast in polarity (no 'not' vs. sí 'yes').

$$
\begin{aligned}
& \text { Aquí no compró nada ninguno de ellos, pero en Guanajuato sí } \\
& \text { here not bought nothing none of them but en Guanajuato yes } \\
& \left\{{ }^{*} \text { María }\right\} \text { dejó todos sus ahorros \{María\}. } \\
& \text { Mary left all her savings } \\
& \text { 'None of them bought anything here, but Mary did leave all of her savings in } \\
& \text { Guanajuato.' }
\end{aligned}
$$

This strongly indicates that sí in such cases is an emphatic affirmative polarity element, which given its focal character, requires subject-verb inversion. Overall, the evidence adduced in the preceding paragraphs confirms that both si que/ $\emptyset$ and si exist in Colombian, Mexican, and Peruvian Spanish, although the difficulty in distinguishing the two of them in certain contexts is undeniable. We now turn to the analysis of sí $\emptyset$.

\section{On the analysis of si $\emptyset$ and PF spellout}

Taking the account of Iberian Spanish sí que in (7) as our point of departure, we provide arguments that in those Latin American varieties in which que need not be expressed overtly in the sí-que construction, the syntactic analysis proposed for Iberian Spanish in (7) can fully be maintained, which should be taken to be a strong (and novel) argument in its favor. The difference between Latin American Spanish varieties where que might be missing and Iberian Spanish is that que can receive a silent/null PF spellout in Latin American varieties, as in (28). ${ }^{14}$ This line of analysis dates back in spirit to the seminal work of Chomsky \& Lasnik (1977), wherein that in English sentences where it can be omitted without semantic consequences (I think that the CP is cool vs. I think the CP is cool) is the result of that-deletion.

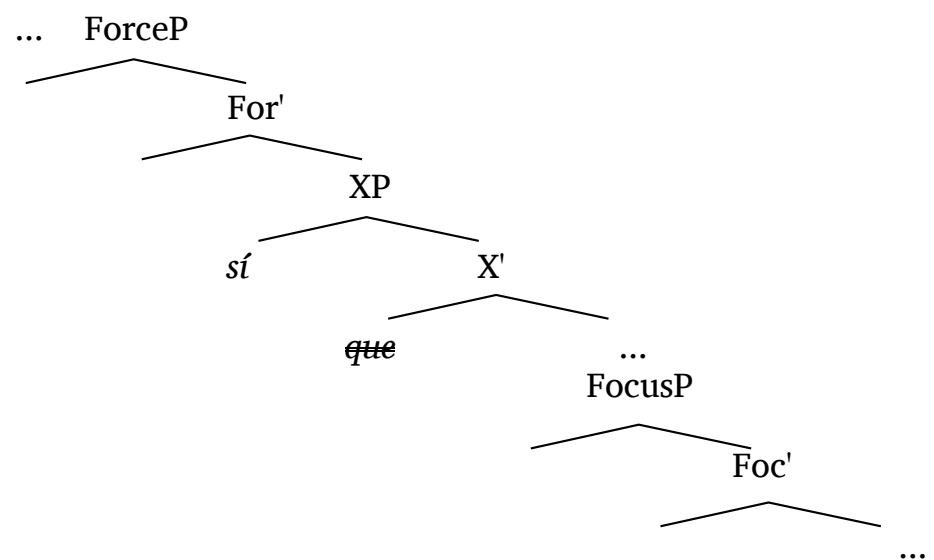

\footnotetext{
${ }^{14}$ In the sí-que sequence, sí appears to be the most important element to obtain the relevant semantic interpretation in the varieties in question. This makes sense intuitively, since the complementizer que is the most underspecified element in the left periphery (Villa-García 2015) and it can occur in various positions along the left-edge spine. Thus, it is not surprising that if one of the two elements can be omitted, it is que and not sí that remains unpronounced.
} 
Before entertaining this hypothesis, however, there is a potential competing account which needs to be excluded.

\subsection{Ruling out an alternative analysis}

Prima facie, the by-now familiar sí-no combination in Colombian, Mexican, and Peruvian Spanish would in principle be amenable to an analysis whereby sí occupies FocusP (presumably it would have to be base-generated there) and no is located in $\Sigma$ P, by virtue of the fact that it marks the negative polarity of the clause. This possibility is schematized in (29):

$$
\left[_ { \text { ForceP } } \left[\left[_{\text {TopicP }} X P\left[_{\text {TopicP }}\left[\left[_{\text {FocusP }} \text { sí }\left[\Sigma \text { no }\left[\left[_{\text {TP }} \ldots\right]\right]\right]\right]\right]\right]\right.\right.\right.
$$

On this view, then, the two items (sí and no) may be able to co-occur in the same clause. This would assume that sí does not signal a commitment on the part of the speaker to the truth of the proposition - perhaps it is just a focal, emphatic affirmative polarity marker, contra the judgments of the speakers consulted. Beyond meaning, this alternative account of the sí-no sequence is also weakened on syntactic grounds by the fact that sí can be followed by an unambiguous adverb stressing the truth value of the proposition that follows it in the relevant Latin American varieties, as in (30). ${ }^{15}$

$$
\begin{aligned}
& \text { A la fiesta sí ciertamente/ desde luego no voy a ir. } \\
& \text { to the party yes certainly of course not go to go } \\
& \text { 'I will certainly not go to that party.' }
\end{aligned}
$$

Similarly, this piece of data crucially indicates that sí in this context is indeed not a focal marker, since it does not require adjacency with the verb (see the preceding section).

Moreover, under (29), we would expect to find no-sí sequences if the facts reduced to a matter of focal polarity particle + polarity particle. However, the CREA corpus does not contain any instance of the no-sí combination in any dialect of Spanish. The corpus searches, coupled with the introspective judgments of our native-speaker consultants, suggest that no-sí sequences are fully ungrammatical, as (31) and (32) demonstrate. Note that speakers find these sentences not only syntactically ill-formed, but they actually fail to assign them a plausible interpretation.

$$
\begin{aligned}
& \text { a. *A eso no sí puedo acostumbrarme, al chocolate malo. } \\
& \text { to that not yes can get.used to.the chocolate bad } \\
& \text { b. *Eso no sí sé. } \\
& \text { that not yes know } \\
& \text { a. *Pero de pestilencia no sí te escapas. } \\
& \text { but of stench not yes CL escape } \\
& \text { b. *Ahí no sí se tendrá en cuenta el proceso de apertura. } \\
& \text { there not yes CL will.take into account the process of opening }
\end{aligned}
$$

This is scarcely surprising if sí in the relevant Latin American Spanish examples does not really mark polarity, in much the same way as its sí-que homolog in Iberian Spanish, which is our claim here, contra (29). No in Spanish, for its part, can only mark negative polarity, and thus the presence of sí creates a contradiction. More generally, the ungrammaticality of (31) and (32) is owing to syntactic and semantic reasons: on the one hand, si and no compete for the same base-generated position, since both are polarity particles initially merged directly in $\Sigma$ P (Hernanz 2007, inter alia); on the other hand, the two

\footnotetext{
${ }^{15}$ Not surprisingly, this example is completely out in Iberian Spanish unless que occurs.
} 
polarity particles cannot co-occur because a clause cannot bear contradictory polarity values simultaneously. Thus, the data above rule out an analysis along the lines of (29) wherein both sí and no in (31) and (32) are polarity markers. The alternative order, sí no, is possible in the relevant varieties because the high element sí is not really a polarity marker, but the sí of sí que in XP, whilst no is a polarity marker located in $\Sigma \mathrm{P}$. Thus, we propose that the sentences in which sí is followed by no (cf. (18), (20), and (30)) are nullque variants of the si-que-no sequence. Consequently, the analysis proposed for si-que cases can be maintained for their que-less counterparts, as in (33) (see also (28)). ${ }^{16}$

$$
\left[_{\text {ForceP }}\left[_{\text {TopicP }}\left[{ }_{\mathrm{XP}} \boldsymbol{s i ́}\left[_{\mathrm{X}^{\mathrm{o}}} \boldsymbol{q u \boldsymbol { e }}\left(\left[_{\text {TopicP }}\left[_{\mathrm{FocusP}}\right)\left[_{\Sigma \mathrm{P}} \text { no }\left[_{\mathrm{TP}} \cdots\right]\right]\right]\right](]\right)\right]\right]\right.
$$

As a reviewer kindly points out, it is important to consider the possibility of having nullque variants in other environments. In this regard, Martínez Vera (2019) argues that Latin American Spanish varieties lack overt que in the double-que (i.e., recomplementation) construction found in Iberian Spanish, as investigated by Villa-García (2015). As Michelle Sheehan (pers. comm.) observes, perhaps Latin American varieties are more permissive in terms of the omission of que as a $\mathrm{C}$ head more generally. Thus, the phenomenon discussed here seems to be an instantiation of a more general case (see also fn. 5 for much relevant discussion). In essence, the omission of que in si-que environments is not an isolated case in the left periphery of Spanish; other $C^{\circ}$ s can be overt and null as well (Villa-García in preparation).

\subsection{Back to si que in the relevant Latin American varieties: Arguments}

Given that the sí que - sí $\varnothing$ alternation seems to be in free variation in varieties such as Colombian and Mexican Spanish (cf. (15)-(17)), a natural way of analyzing the relevant cases is to assume, as we are doing here, that que can remain silent or, put differently, that the head of XP —under the analysis currently pursued — does not have to be spelled out under normal circumstances. Since the semantic contribution and the syntactic behavior of sí $\varnothing$ in such varieties mirror those of sí que in Iberian Spanish, it follows that the two elements should be analyzed similarly, precisely as assumed by our proposed account in (33). In the following paragraphs, we provide support for the claim that the absence of que reduces to a case of null PF spellout.

Indeed, that the overtness or non-overtness of que in the si-que sequence has to do with PF realization of the complementizer is supported by the following facts. First, the optional presence of que has no semantic effect in the Latin American varieties at issue, which is wholly compatible with its realization being reducible to PF considerations. ${ }^{17}$ Additionally, remember that in Iberian Spanish, sí que can in principle be followed by a proposition that itself contains an emphatic positive polarity marker, thus making the sequence sí que sí legitimate. If some varieties of Latin American Spanish permit the omission of que, as we have seen, then the prediction is that such varieties should in theory allow sí-sí sequences. The reason is that the first instance of sí would be in Spec,XP and the second instance would be the focal positive polarity marker located in FocusP, making the two items compatible in principle. However, the CREA corpus does not contain any examples of sí sí in Colombian Spanish, and the same result holds for Mexican Spanish. This fact leads us to suggest that the prediction that the combination sítsi should in theory be possible is not borne out, as shown by (34). This result resonates with the judgments

\footnotetext{
${ }^{16}$ As Villa-García \& González Rodríguez (2020) point out, it may well be the case that in some contexts no can also be focal and thus move to FocusP. Since nothing bears on this issue for purposes of our present claims, we will deliberately set aside this possibility here. See also fn. 9 on no que no.

${ }^{17}$ As is usually the case with elements that can be overt or null without apparent semantic differences, when asked about potential meaning differences, speakers tend to point out that there is a difference in the degree of emphasis, with overt elements (sí que) indicating added emphasis.
} 
of our native-speaker consultants from different varieties, who categorically reject such sentences, regardless of whether or not ellipsis is effected.

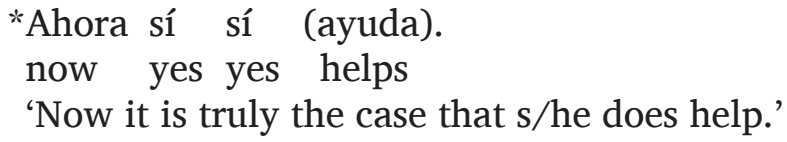

This may seem like a counterexample to the analysis proposed here, but in fact it constitutes strong evidence in its favor: in such contexts, que has to surface obligatorily for speakers of the aforementioned varieties, who find que non-compulsory (and in fact tend to omit it) in other contexts. Thus, the grammatical counterpart of (34) is identical to the Iberian Spanish version, provided in (35).

$$
\begin{aligned}
& \text { Ahora sí que sí (ayuda). } \quad \text { (= (23)) } \\
& \text { now yes that yes helps } \\
& \text { 'Now it is truly the case...' }
\end{aligned}
$$

The fact that que needs to be overt in sí-sí contexts but not in sí-no contexts (cf. (18)) confirms that we are dealing here with an instance of the si-que construction. ${ }^{18}$ One natural explanation for the contrast between sí no and "sí sí is to assume that whereas que can remain phonologically unrealized in the first case, it cannot in the second, possibly due to a constraint against adjacent homophonous forms (i.e., haplology). This is in keeping with the judgments of our consultants, who intuitively deem sí-sí sentences overly cacophonic. As a result, que must be PF-realized in order for the illicit sí-sí sequence to be disrupted (i.e., sí que sî.). ${ }^{19,20}$

Lastly, that sí-sí sequences are ruled out on phonological grounds and not because sí que is incompatible with a focal polarity particle immediately below it is corroborated by the example in (36), which features the focal polarity particle tampoco 'neither' after sí que. Put another way, while the presence of the emphatic affirmative polarity sí requires que to surface to avoid contiguous sí sí forms, other focal polarity particles causing no haplology issue do not trigger the overt realization of the complementizer in between items:

(Miguel Torres, El incendio de abril, Alfaguara, Colombian Spanish, 2012)

Ponerse uno contento de que lo mataran, eso sí tampoco. becoming-CL one happy of that CL killed that yes neither '...getting happy because they killed him, that cannot be the case either.'

\footnotetext{
${ }^{18}$ Again, these cases should be distinguished from those involving proform sí, followed by a clause, which may include the emphatic affirmative polarity marker (and which are found across Spanish varieties). Here, the adjacency between sís is disrupted by the presence of the prosodic boundary (see also (4) above):
}

(i)

$$
\begin{aligned}
& \text { Sí, sí gané. } \\
& \text { yes yes won } \\
& \text { 'Yes, I did win.' }
\end{aligned}
$$

Note that (i) further contributes to the distinction drawn above between proform sí and emphatic-polarityencoding sí: structurally, the former is higher than the latter and the two can occur in the same sentence concurrently.

${ }^{19}$ In this sense, this would be comparable to Spanish cases where an expletive (i.e., meaningless) no is inserted to avoid contiguous homophonous forms, as in (i).

(i) Que vengas es mejor que (no) que te quedes. that come $_{\text {Subs }}$ is better than not that CL stay 'For you to come (here) is better than staying.'

Though optional, no is usually employed in order to avoid the (stylistically dispreferred) adjacent realization of two homophonous complementizers (RAE-ASALE 2009).

${ }^{20}$ In fact, see Villa-García (2015 et seq.) and references therein for the prospect that (non-)PF-realization of an element can help ameliorate violations. 
The existence of examples like (36) further strengthens the parallelism with Iberian Spanish sí-que patterns, which can also be followed by emphatic polarity-encoding elements like tampoco and también (see Villa-García \& González Rodríguez 2020, for empirical evidence; see also (13)a). ${ }^{21}$

The facts just reviewed lend plausibility to an account wherein que is in principle optional in the si-que sequence in most contexts in Latin American varieties such as Colombian and Mexican Spanish, thus reducing its presence or absence to a PF matter. ${ }^{22}$ Further, a welcome advantage of this analysis is that it allows for a unified account of sí que and sí $\varnothing$ across dialects.

\subsection{Excluding a lexical account (sí que vs. si $\emptyset$ )}

In this subsection, we would like to briefly consider an alternative account to derive the sí que case. This competing analysis is outlined in (37):

$$
\left[_{\mathrm{ForceP}}\left[_{\mathrm{TopicP}}\left[{ }_{\mathrm{XP}} \boldsymbol{s i ́}\left[_{\mathrm{X}^{\circ}} \boldsymbol{q u e} / \emptyset\left[_{\mathrm{TP}} \cdots\right]\right]\right]\right]\right.
$$

Under the proposal in (37), que and $\emptyset$ are distinct lexical items, rather than a single lexical item with two different spellouts, namely an overt spellout (i.e., que) and a null spellout (i.e, que), as assumed under our account (cf. (33)).

Nonetheless, arguments such as the following seem to favor the null-que analysis in (33) over the two-different-lexical-items analysis in (37): in Colombian, Mexican, and Peruvian Spanish, que in sí que always seems to be an option, in that we have found no cases involving sí $\varnothing$ as a way of signaling the speaker's commitment to the truth of the proposition where que would have to remain absent. In other words, it seems that que is always pronounceable. Moreover, the analysis in (37) would be at variance with the facts reviewed above where on occasion, que must be spelled out owing to PF reasons (cf. $(34) /(35))$. In this connection, in a model wherein syntactic structure is sent to PF and to $\mathrm{L}$ (ogical)F(orm), and PF checks whether the structure adheres to PF requirements such as the avoidance of contiguous homophonous forms (e.g., sí sí), it is not at all clear how the head $\varnothing$ could end up being spelled out as que in such cases (since under this account, que and $\varnothing$ are different lexical items, not just the result of two different spellouts of the same item). On this view, we would have to stipulate that que, as a maximally underspecified left-peripheral form (Villa-García 2015), is an expletive inserted in PF, much like contentless/expletive no 'not' in (i) in fn. $19 .{ }^{23}$ Although we will defer further discussion of this alternative account for future work due to space limitations, it appears that the que alternative provides a more straightforward account of the sí-que-sí facts (as well as a unitary

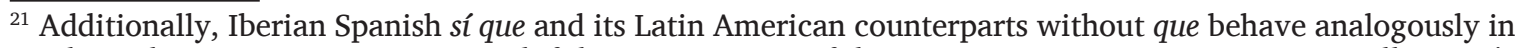
other relevant respects, as expected if they are variants of the same construction. For instance, Villa-García \& González Rodríguez (2020) show that sí-que sequences, which are assumed under (33) to involve more $\mathrm{CP}$ structure than polarity-sí configurations, cannot readily appear in CPs with a defective structure that projects only up to FocusP (de Cuba \& MacDonald 2013). Defective CPs include factive sentences. This predicts that sí $\varnothing$ should be illegitimate under factive predicates in the Latin American dialects in question, in much the same way as sí que in Iberian Spanish. This is borne out by (i):
}

$$
\begin{aligned}
& \text { *Me atormenta el hecho de que sí la Roberta no venga. } \\
& \text { CL torments the fact of that yes the Roberta not come } \\
& \text { Intended reading: 'The fact that it is truly the case that Roberta doesn't come bothers me.' }
\end{aligned}
$$

However, as noted by an anonymous reviewer, further research should ascertain this point, since there seems to be a high degree of inter-speaker variation in terms of the selectional requirements of factive predicates more generally (see also Villa-García 2019).

22 Something along the same lines may occur in the case of the seemingly lexicalized expression no que no found in certain varieties, where que must be present (see fn. 9).

${ }^{23}$ An account along these lines is in fact usually assumed for the English expletives it/there and even for do in do-support (see, among others, the discussion in Bošković 2007 and Radford 2016). 
treatment of the facts across dialects), and in actuality the account in (33) fares rather well with the account of micro-variation to be pursued in the following subsection. More generally, our findings provide additional cross-dialectal support for the analysis of sísí que proposed in Villa-García \& González Rodríguez (2020), which in turn is based in part on previous accounts in the literature (e.g., Hernanz 2007; Batllori \& Hernanz 2013).

\subsection{Toward a (micro-)parameterization of the dialectal contrast}

The approach adopted here (cf. (33)) coheres well with the claim made by Rizzi (2013: 201-202) and Rizzi \& Bocci (2017: 13) that in some cases, the difference between overt and null C/left-peripheral heads (i.e., que/que) can be attributed to a superficial spell-out (i.e., pronunciation) parameter, which we would like to recast also as a micro-parameter accounting for intra-linguistic differences (see, e.g., Kandybowicz 2009; Chomsky 2010; Richards 2010; Berwick \& Chomsky 2011; and Boeckx 2012, for an approach that treats linguistic variation as a matter of externalization). In the words of Rizzi (2013: 201-202), this is "a familiar and widely attested kind of low-level parameterization." This (micro-) parameter would thus lie at the heart of the observed dialectal split between Iberian Spanish sí que on the one hand, where que is overt, and Latin American si que/que, on the other, where que can receive a silent spellout, hence accounting for its optional character. On this view, the presence or absence of que in sí que would be a matter of PF: whereas in Iberian Spanish, que requires an overt spellout, in some Latin American varieties at least, it can receive a silent/null spellout in most contexts, a view for which we have provided empirical support in the preceding subsections. This approach to micro-variation is indeed in keeping with Barbiers (2009) contention that variation more generally is restricted to lexical properties and PF spellout (see also the abovementioned references). Further research will determine whether this approach is extendable to other left-peripheral heads $/ \mathrm{C}^{\circ}$ s.

As an alternative account of the observed microvariation, Adger \& Smith (2005 et seq.) advocate the view that the feature system assumed in much work in Minimalism in the last three decades allows for variable phonetic (i.e., audible) outputs with the same interpretation (in our case, que and its null counterpart, que), by virtue of a particular head containing one additional formal feature, with visible phonetic consequences but not semantic ones. For reasons of space, we will not explore this alternative possibility here. Further research will draw a comparison between competing accounts of microvariation in sí que/que cases.

\section{Conclusion}

In this paper, we have focused on the previously unnoticed dialect contrast between Iberian Spanish sí que vs. Colombian, Mexican, and Peruvian Spanish sí que/ $\emptyset$, a construction used to herald the speaker's commitment to the truth of the proposition embedded under sí que/Ø. We have shown that sí as an emphatic affirmative polarity marker is attested across Spanish varieties. The diatopic contrast therefore relates to sí que/Ø, with the sí-que version being obligatory in Iberian Spanish, and que being generally optional in Latin American varieties like Colombian, Mexican, and Peruvian Spanish. More generally, the morphological realization of distinct CP-related heads as que along the left periphery across Spanish dialects is a topic of ongoing research at present (see, e.g., Villa-García 2015, in preparation).

Based on recent accounts of the sí-que phenomenon in Iberian Spanish, we have argued that the analysis pursued in Villa-García \& González Rodríguez (2020) can straightforwardly be applied to the relevant Latin American varieties, the difference between said varieties being the PF (non-)realization of the relevant head que (i.e., sí que/que). We have provided empirical arguments that this is the case from a number of Latin American varieties using data drawn from a variety of sources and considered alternative 
theoretical proposals, which fail short of explaining the relevant facts. Therefore, the data presented here lend novel support to Villa-García \& González Rodríguez's recent account of the Iberian Spanish facts, which allows for a unitary analysis of the different dialectal possibilities.

We have also shown that the data brought to light herein are wholly consistent with a view of (micro-)parameterization whereby variation is restricted to lexical properties and, crucially for the sí que/ $\varnothing$ case, PF spellout (que/que), although the dialectal data may also be amenable to feature-based accounts. More generally, our discussion has shown that the phenomenon investigated here has wide-ranging consequences for a host of longstanding issues in morphosyntax, including word order possibilities, ellipsis, polarity, lexical realizations, microvariation, and the structure of the clausal left edge.

\section{Abbreviations}

ACC $=$ accusative, $\mathrm{CL}=$ clitic, SUBJ $=$ subjunctive.

\section{Acknowledgements}

We are extremely grateful to three anonymous Glossa reviewers for their critical, thorough, useful, and encouraging observations during two rounds of reviews. We are also thankful to a Studies in Hispanic and Lusophone Linguistics anonymous reviewer for encouraging us to expand a section into a larger paper. This paper also owes much to the audiences at the Universidad Complutense de Madrid (especially Luis García Fernández, Isabel Pérez Jiménez, and Cristina Sánchez López); the University of Geneva (especially Guliano Bocci and Luigi Rizzi), the University of Manchester (especially Delia Bentley, Ricardo Bermúdez-Otero, Simone De Cia, Vera Hohaus, and John Payne); the $2^{\text {nd }}$ Spanish Dialects Meeting (Universidad de Castilla-La Mancha); the Syntactic Variation in Romance: Formal Approaches to Romance Microvariation (FARM) workshop at the University of Bucharest (especially Michelle Sheehan and Sam Wolf); and the $2^{\text {nd }}$ Student Conference in Latin American Studies (SCOLAS) at Leiden University (especially Carme Parafita Couto and Nanne Timmer). Thanks to our native-speaker consultants and to Franciso A. Eissa-Barroso, Valentino Gianuzzi, Santiago González y FernándezCorugedo, Jonathan MacDonald, Francisco Martín Miguel, Gabriel Martínez Vera, Miguel Rodríguez Mondoñedo, and Hugo Sánchez-Llana for useful data and discussion alongside help recruiting native-speaker consultants. Thanks are also due to the University of Manchester Library for providing the necessary institutional funds to cover the cost of Open Access for this paper. Special thanks to Johan Rooryck and his editorial team for their unremitting support and editorial assistance with this project.

\section{Competing Interests}

The authors have no competing interests to declare.

\section{References}

Adger, David \& Jennifer Smith. 2005. Variation and the Minimalist Program. In Leonie Cornips \& Karen Corrigan (eds.), Syntax and variation: Reconciling the biological and the social, 149-178. Amsterdam: John Benjamins. DOI: https://doi.org/10.1075/ cilt.265.10adg

Ambar, Manuela. 2002. Wh-questions and wh-exclamatives: Unifying mirror effects. In Claire Beyssade, Reineke Bok-Bennema, Frank Drijkoningen \& Paola Monachesi (eds.), Romance Language and Linguistic Theory 2000, 15-40. Amsterdam: John Benjamins. DOI: https://doi.org/10.1075/cilt.232.03amb

Barbiers, Sjef. 2009. Locus and limits of syntactic microvariation. Lingua 119. 1607-1623. DOI: https://doi.org/10.1016/j.lingua.2008.09.013 
Batllori, Montserrat \& M. Llüisa Hernanz. 2013. Emphatic polarity particles in Spanish and Catalan. Lingua 128. 9-30. DOI: https://doi.org/10.1016/j.lingua.2012.11.010

Berwick, Robert C. \& Noam Chomsky. 2011. The biolinguistic program: The current state of its development. In Anna Maria Di Sciullo \& Cedric Boeckx (eds.), The biolinguistic enterprise: New perspectives on the evolution and nature of the human language faculty, 19-41. Oxford: Oxford University Press.

Boeckx, Cedric. 2012. The emergence of language from a biolinguistic point of view. In Kathleen R. Gibson \& Maggie Tallerman (eds.), The Oxford Handbook of Language Evolution, 492-501. Oxford: Oxford University Press. DOI: https://doi.org/10.1093/ oxfordhb/9780199541119.013.0052

Bošković, Željko. 2007. On the locality and motivation of move and agree: an even more minimal theory. Linguistic Inquiry 88. 589-644. DOI: https://doi.org/10.1162/ ling.2007.38.4.589

Brucart, Jose M. 1999. La elipsis. In Ignacio Bosque \& Violeta Demonte (eds.), Gramática descriptiva de la lengua española, 2787-2863. Madrid: Espasa Calpe.

Campos, Héctor. 1992. Los bearneses que quequean, ¿y nosotros, que? Hispanic Linguistics 4. 329-349.

Carbonero Cano, Pedro. 1980. Afirmación, negación, duda. Revista de la Sociedad Española de Lingüística 10. 161-175.

Chomsky, Noam \& Howard Lasnik. 1977. Filters and control. Linguistic Inquiry 8. 425-504.

Chomsky, Noam. 2010. Some simple evo-devo theses: How true might they be for language? In Richard K. Larson, Viviane Déprez \& Hiroko Yamakido (eds.), The evolution of human language: Biolinguistics perspectives, 45-62. Cambridge: Cambridge University Press. DOI: https://doi.org/10.1017/CBO9780511817755.003

de Cuba, Carlos \& Jonathan E. MacDonald. 2013. On the referential status of embedded polarity answers in Spanish. In Jennifer Cabrelli Amaro, Gillian Lord, Ana de Prada Pérez \& Jessi Elana Aaron (eds.), Proceedings of the $16^{\text {th }}$ Hispanic Linguistics Symposium, Somerville, 312-323. MA: Cascadilla.

Depiante, Marcela. 2004. Dos casos de elipsis con partícula de polaridad en español. Rasgal 1. 53-69.

González Rodríguez, Raquel. 2009. La expresión de la afirmación y la negación. Madrid: Arco/Libros.

Haegeman, Liliane \& Virginia Hill. 2013. The syntactization of discourse. In Raffaella Folli, Christina Sevdali \& Robert Truswell (eds.), Syntax and its limits, 370-390. Oxford: Oxford University Press. DOI: https://doi.org/10.1093/acprof: oso/9780199683239.003.0018

Hernanz, M. Llüisa. 2007. From polarity to modality: Some (a)symmetries between bien and sí in Spanish. In Luis Eguren \& Olga Fernández-Soriano (eds.), Coreference, modality, and focus, 133-170. Amsterdam: John Benjamins. DOI: https://doi. org/10.1075/la.111.08her

Hualde, José Ignacio, Antxon Olarrea, Anna María Escobar \& Catherine E. Travies. 2010. Introducción a la lingüística hispánica. New York: Cambridge University Press. DOI: https://doi.org/10.1017/CBO9780511808821

Jiménez-Fernández, Ángel Luis \& Selçuk Issever. 2019. Politeness marking and the syntax of discourse. MIT Working Papers in Linguistics 90. 129-136.

Kandybowicz, Jason. 2009. Externalization and emergence: On the status of parameters in the Minimalist Program. Biolinguistics 3. 93-98.

Leonetti, Manuel \& María Victoria Escandell-Vidal. 2009. Fronting and verum focus in Spanish. In Andreas Dufter \& Daniel Jacob (eds.), Focus and background in Romance Languages, 155-204. Amsterdam: John Benjamins. DOI: https://doi.org/10.1075/slcs.112.07leo 
Martínez Vera, Gabriel. 2019. Phases, labeling, antilocality and intonational phrases: Recomplementation in Spanish. Probus 31. 187-231. DOI: https://doi.org/10.1515/probus-2019-0002

Miyagawa, Shigeru. 2017. Agreement beyond phi. Cambridge, MA: MIT Press. DOI: https:// doi.org/10.7551/mitpress/10958.001.0001

Poletto, Cecilia \& Raffaella Zanuttini. 2013. Emphasis as reduplication: Evidence from sì che/no che sentences. Lingua 128. 124-141. DOI: https://doi.org/10.1016/j.lingua.2012.10.016

Radford, Andrew. 2016. Analysing English sentences. 2nd edition. Cambridge: Cambridge University Press. DOI: https://doi.org/10.1017/CBO9780511980312

RAE \& ASALE. 2009. Nueva gramática de la lengua española. Madrid: Espasa Calpe.

Richards, Norvin. 2010. Uttering trees. Cambridge, MA: MIT Press. DOI: https://doi. org/10.7551/mitpress/9780262013765.001.0001

Rizzi, Luigi. 1997. The fine structure of the left periphery. In Liliane Haegeman (ed.), Elements of grammar, 281-337. Dordrecht: Kluwer. DOI: https://doi.org/10.1007/97894-011-5420-8_7

Rizzi, Luigi. 2013. Notes on cartography and further explanation. Probus 25. 197-226. DOI: https://doi.org/10.1515/probus-2013-0010

Rizzi, Luigi \& Giuliano Bocci. 2017. The left periphery of the clause. In Henk van Riemsdijk \& Martin Everaert (eds), The companion to syntax, 1-30. Oxford: Blackwell. DOI: https://doi.org/10.1002/9781118358733.wbsyncom104

Villa-García, Julio. 2015. The syntax of multiple-que sentences in Spanish: Along the left periphery. Amsterdam: John Benjamins. DOI: https://doi.org/10.1075/ihll.2

Villa-García, Julio. 2019. Recomplementation in English and Spanish: Delineating the CP space. Glossa: a journal of general linguistics 4(1) 56. 1-44. DOI: https://doi. org/10.5334/gjgl.845

Villa-García, Julio. In preparation. $\mathrm{C}^{\circ}$ realizations along the clausal left-edge across the Spanish-speaking world. Ms., University of Manchester.

Villa-García, Julio \& Raquel González Rodríguez. 2020. On the contrasts between sí 'yes' and si que 'yes that' in Spanish and the structure of the Complementizer Phrase domain. Studies in Hispanic and Lusophone Linguistics 13(2). 451-484. DOI: https://doi. org/10.1515/shll-2020-2037

Wiltschko, Martina \& Johannes Heim. 2016. The syntax of confirmationals. A neo-performative analysis. In Gunther Kaltenböck, Evelien Keizer \& Arne Lohmann (eds.), Outside the clause. Form and function of extra-clausal constituent, 303-340. Amsterdam: John Benjamins. DOI: https://doi.org/10.1075/slcs.178.11wil

How to cite this article: Villa-García, Julio and Raquel González Rodríguez. 2020. Dialectal variation in the expression of que in si-que 'yes that' contexts across Spanish: The case of some Latin American Spanish varieties. Glossa: a journal of general linguistics 5(1): 99.1-20. DOI: https://doi.org/10.5334/gjgl.1186

\section{Submitted: 05 January $2020 \quad$ Accepted: 30 June $2020 \quad$ Published: 08 October 2020}

Copyright: $\odot 2020$ The Author(s). This is an open-access article distributed under the terms of the Creative Commons Attribution 4.0 International License (CC-BY 4.0), which permits unrestricted use, distribution, and reproduction in any medium, provided the original author and source are credited. See http://creativecommons.org/licenses/by/4.0/. 